\title{
Major Challenges in English Language Teaching in Fulfilling the Industry Needs
}

\author{
K.Gurusamy, A.Gokula Hari
}

\begin{abstract}
English is globally accepted as "Trade Language". This is due to the emergence of English to its current position from its day of emergence considerably a small span of time due to the business strategy and establishment followed by its natives. English now enjoys the position of being the leading language of International discourse and the lingua franca in many regions and professional contexts such as Science, Navigation, Law etc. It has been used as a second language or official language in almost sixty sovereign nations. Of them India is one among the fast growing and technologically self-satisfied globally admired nation. Several nations including the developed have acknowledged the IQ of Indian individuals and their contribution towards the global development. But it is also a fact that many of the Indian students due to their lack in Communication skills has left themselves to stay on meagre grounds. The intellect and knowledge acquired in them has been made to stagnate due to the absence of the channel "Communication". It is due to our education system that has its base on testing memory skills rather to check on and develop latent skills. This practice has led to the reports filed by organizations on which the denial of employment is due to the lack in not of technical criteria but of the soft skills. These situations have now become a common criterion in several branches, especially in Engineering. Thus focus should be given on both the academic as well as communicative areas.
\end{abstract}

Keywords - Communication Skills, Education, Engineering, English, Industry needs

\section{INTRODUCTION}

The Indian educational system has undergone several changes in its period of evolution. The flexibility practiced by the education system enables it to notice as well as make changes to improve the quality of learning process periodically. Though the education system functions effectively in monitoring and accelerating the effects on the learners and the efficiency of the practices followed, the desired outcome has not yet been achieved. The students are getting only a little bit of knowledge. During the past, English is taught just like a

library language, because of its utilization necessary only for clerical needs. But now that concept has been changed totally. The emergence of English in almost all the fields and the vast spreading of the language have made it necessary a means to get global reorganization. This resulted in an indirect stress on the teaching English and acquiring the language.There is a shift in teaching and learning process as the aim of teaching a subject shifts. From the level of a

Revised Manuscript Received on December 20, 2019.

Dr. K.Gurusamy , Associate Professor, Department of English, Kalasalingam Academy of Research and Education, Madurai, India, k.gurusamy@klu.ac.in

Mr.A.Gokula Hari, Research scholar, Department of English, Kalasalingam Academy of Research and Education, Madurai, India, aghari93@gmail.com clerical language it has shifted to a language of proficiency. Thus spontaneity and proficiency is aimed at the teaching of English. But the desired result has not been attained. According to A.K. Sharma, English Language teaching in India has been facing a lot of problem, which the students who have passed in higher secondary or degree examinations with English as a compulsory subject or as an elective can neither speak nor write in exact English. Because in our schools and colleges the weightage is given on the theoretical content and the technical content is neglected so far. [1]

\section{ENGLISH AND ENGINEERING}

Engineering is a multi-dimensional study with social, political, ethical and economical outset. It is believed that the engineering has been one among many reasons through which our nation established itself in a universal scale of techno developed countries. Engineering as an education has nowadays been the area of choice for most youngsters that have a love for science. It is a well-known fact that Engineering is not a moral educating criterion but something advanced. It has its scope towards the industry needs which includes communication and response skills i.e soft skills too. The growing of Engineering Institutions year after year all over the world including India exposes the growth of this field in almost all branches of sciences. But it is a contradicting fact about the employability of candidates depletes with the increase in demand of this field. Though many students have the content in them, their language proficiency and mannerism plays a vital role in getting them placed. It is an acceptable fact that in nations like India where there prevail a number of diversities, one cannot expect students to have the same level of assertiveness in them. But in consideration to the aim they possess, it is their duty as well as their trainer's duty to enhance their soft skills to have them placed According to Lumsdaine and Lumsdaine, the Employment opportunity for the Engineering graduates' warrants for a variety of skills, including visualization and communication skills. [2]

The Industries expect their employees to possess the following skills. An employee

- Can learn themselves

- Can work independently and also in a team.

- Can work under pressure.

- Can be initiative, adaptability and tolerance.

- Can have good communication skills.

- Can apply field specific theoretical knowledge.

- Can involve personally.

- Can work with loyalty and integrity.

- Can think critically. 
- Can approach problems in a brilliant manner

- Can be a creative and imaginative thinker.

But the existing condition poses the question "Do the Engineering Institutions produce Engineers with Employability skills, otherwise known as Non-technical skills?" This question by the organizations to the institutions shows that there is a presence of a hole which arises due to the missing of the Non-technical skills within their employees. Thus this is considered as the most challenging question by the Industrialists to the Institutions. To one's dismay the answer found is that the international studies proclaim that at the entry level engineering employees are incompetent in the broader non-technical skills.

Narsee, confirms this view saying that Employers have a feeling that the educational institutions should concentrate more emphasis on teaching the so called soft skills. [3]

In the glow of employability skills, irrespective of field or subject, there is always a skill gap between the skills expected by the Industry and what is actually on hand with the graduates. This is a phenomenon applicable to all the areas at all times. The main feature contributing to the above phenomenon is the ever dynamic and fast changing organizational climate and workforce requirement. The issue of skill gap seems to get complicated in the present day environment due to innumerable factors such as globalization, technological developments, fast growing field of computer science and technology, multi-cultural working environments, international competition and demands of the present generation etc. Among the skills expected from the industries, only very few skills are being taught in almost all the Engineering institutions i.e communication skills, team work, applying the theoretical knowledge and rest of them they have to get practice by themselves. Though initiatives and measures are in the continuous updating process at all the levels, they are not able to reduce the skill gap. The more attempts are tried to bridge the gap, the more requirements go on increasing. Hence, the problem of skill gap permits for a continuous observation and vigilance are required in this area to bridge the gap and meet the industry needs. A mismatch between the industry needs and the competence of entry level engineers do exist. National Governments and International Engineering bodies have been growing standards and analyze reports periodically in order to support the engineering institutions to bridge the gap. The Government of India is aware of the core of the problem and is on the move to introduce legislation in the context of bridging the skill gap.

\section{BRIDGING THE GAP}

Regarding the steps for improving the situation and enhancing the standard and excellence in the Engineering education and to encounter the industry requirements and expectations, a lot of changes are on the way to revamp the Educational System in India. Changes have reached the doorsteps through the formation of working groups. The widespread discussion is on the concept of bridging the gap through making provisions for the development of the basic/generic skills and re-engineering of education. All these belong to a top down approach. The problem needs a lowermost up - ex ante approach also. The development should be addressed when the students are young and the philosophical foundations of education should be made stronger with appropriate thoughts towards achieving a wholeness of development in the minds of the students. All these depend on the philosophical foundation of education in its right perspective. Indian tradition of education is, no doubt, has a rich heritage with commendable philosophical base the top of which lies in the Gandhian thoughts.

Luiz stated that, Engineering and technology are the most critical inputs meant for economic growth and competitiveness globally. [4]

Engineering Education directly or indirectly contributes to the Gross Domestic Product of every nation ultimately leading to human welfare. The present day society is much-admired to be an information society or knowledge society or network society. Apart from how it may be called, its most visible element is the rapid development of the information and communication technologies, and the fast increasing amount of information. The society is passing through a transformation. According to Tynjala,

Many organizations have the concept for the development of organization through the new kind of expertise. Now they have turned into knowledge intensive and innovative centers They thought that from which they can do networking, collaborative work, and transformative and creative learning. [5]

This change affects the engineering education also. The educational program of a nation should aim at facing and solving the problems and improving the economy through the creation of wealth. It is understood that the engineers should contribute to such a wealth creation and decide the future of the nation. Szpytko states that,

The development and the growth of technology has been so rapid that for the first time in our history, we have made many of the rules outdated and much of the infrastructure that serves society's needs today. The globalization has made tremendous changes in the industry. [6]

He further adds that, the advancement of technology, changes of workplace environment can lead to stimulating and satisfying careers that may require being flexible and committed to continuing professional development

According to Grabowski in the 21 st century engineering education must prepare the students, to face the future technologists and real time world problems, and to satisfy the industry needs. The graduate students must be ready to face the rapidly changing environment, driven by the enhanced rate of technical invention, essential skills for the future, the ability to engage in life-long learning, to communicate and cooperate across disciplines and geographical boundaries. [7]

This phase of the engineering education and industrial needs, seen through the eyes of an engineering student should be on his/her search for a future employee. To meet all the challenges and the expectations of the Industry, Society and Global needs the contribution of English language is the predominant one and learning all the skills in 
English is mandatory for all the Engineering graduates.

\section{ENGINEERING EDUCATION IN INDIA}

The Engineering education in India has its firm foundation since long. A recent publication entitled "Profile of Engineering Education in India" by Biswas Gautam, provides a comprehensive picture of Engineering Education in India. The initial years immediately after Indian independence began to witness a planned development in Engineering Education. The establishment of Indian Institute of Technology by the Government at the centre marked one of the greatest hallmarks of visionary development in the Independent India. On the Recommendations of the Engineering Personnel Committee appointed by the Planning Commission (1955), the Government of India made provisions for the establishment of eight Regional Engineering Colleges (REC) while seven more were added by bringing the total number to fifteen besides strengthening the PG courses and doctoral programs in Engineering. The Thacker Committee (1959-1961), the Nayudamma Committee (1978-79) and The Rama Rao Committee with their recommendations helped the Government add on appropriate values and measures to the refinement of Engineering Education. It was the Rama Rao Committee that supported 'GATE' system of admission and revision of Engineering Curriculum on a practical training orientation. The formation of the All India Council for Technical Education (AICTE) as a regulating body for the conduct of courses in Engineering and Technology, has been working for enhancing the quality of Engineering Education as the Accrediting body also. The number of Engineering Colleges and Deemed Universities in the private sector in India proliferated at a faster rate felicitated by provisions in the National Policy on Education.

The Engineering Education is not only for getting a degree, but also for the acquiring of generic or non-technical skills too. This acquiring of the soft skills is mandatory for every engineering graduate which further exposes their employability. Engineering Education should be able to help a nation achieve higher economic growth rate through effective employment of the Engineering graduates. Industry gives priority to employability skills rather than academic merit alone. The final result is that students may not get placed on the one hand and on the other, industry is not getting proper candidates. Also those who join the industry may not possess the expected competency. To get the expected competency and to meet the industry need it is essential to learn all the four skills in English i.e. Communication skills (LSRW).

\section{THE ROLE OF LSRW}

In the global market highly refined LSRW Skills are very important for the job seekers to get them placed. The ability to communicate is identified as the scale to rank the candidates. This implies the need to have prim set of communicative skills to be a success in any field that a candidate ventures. The recruiters expect technical knowledge backed up by strong communication skills from their job seekers. In the working environment, the nonnative speakers of English feel an urge to use comprehend and manage with their co-workers. Even the assigning of tasks is based on the level of the workers communicating abilities. The reason behind the successful venture of a meagre experienced Team Leader than a veteran of the same field has communication skill as meter. So it is essential to have a better exposure to the world acclaimed global cum trade language English. Acquiring of the same could be done through following the LSRW i.e Listening, Speaking, Reading, and Writing. These skills are most essential for the job seekers in the global market, especially for the Engineering Graduates who are the pillars of the future.

\section{LISTENING, SPEAKING, READING AND WRITING}

Language learning and Language acquiring are the two sides of the same coin. When one acquires their mother tongue, the second language is learned. The difference is one is learned inductively and the other deductively. The mother tongue is learned unconsciously. It initiates with listening and flows towards writing. But it is not so in the case of learning a second language. It actually happens in the reverse and the absence of native speakers takes a severe toll in establishing the listening criterion of the learners. Thus the recent studies has stressed the importance making students acquire the language as they learned their mother tongue by presenting to them various activities and workshops. The learners of the second language have to be given space to experience, enjoy and enlighten themselves by active participation. This implies the natural law of learning through experience.

\section{Listening}

Listening is an active process of receiving and retorting the spoken. The first and the fore most skill for learning any new language is listening. Listening can be the most vital skill, without this intuition we cannot read and write. It is an active process and needs more practice and lot of attention. The objectives of Listening in the Engineering Graduates is

- To learn

- To increase one's understandings

- To advice or council

- To relieve one's boredom-music

- To ensure attention, interpretation, retention and sound motivation.

Communication is not effective and complete without proper listening. An active listener can stimulate the speaking of the speaker. A good listener leisure more than an ordinary listener and he can learn to deflect prejudices, assumptions and attitudes. This enables to expose themselves to various exposures; aiding in the development of their skills. According to a research one third of a day is used for listening in a work place. There is a close relationship between Listening and Speaking. "The listener needs to identify the purposes or the goals of conducting the activity" [8]. Understanding plays, a major role in the process of listening. The next stage or process of a communication would take place only when the message is conveyed clearly. One must listen without any bias and prejudices and open to others view for the success. 
Effective Listening is a self-motivated activity that seeks out the meaning envisioned in the messages. It evaluates the reliability of reasoning, consistency of the supporting materials, calculates the values and risks of accepting their recommendations and to participate. In order to develop the listening skills of the learners, they should be made to experience and acculturate the following by inducing them in various activities.

A) Being open-minded.

- Reputation building body language

- Maintaining eye contact

- Listening without disruption.

B) Listen dynamically.

- Observing the speaker.

- Listening with the curiosity.

- Trying to understand.

- Exposing to intermediate explanation.

C) Responding properly.

- To prepare your responses use top-down listening strategies

- To gather further information and prepare a response use bottom-up Listening strategies.

- Raising questions in an appropriate pause.

- Don't interrupt.

- Providing considerable responses to the speaker.

\section{Speaking}

Speaking is defined as the action of conveying information or expressing one's feelings in speech. It is a method of constructing and partaking meaning through the use of verbal and non-verbal symbols. It is the most exciting skill for students because of the set of features that describe oral treatise. The general problem faced by students is, it is not easy to perform in front of public especially with the pressure to perform, it challenge us to do the best. [9]

Spoken English cannot be planned or organized in advance. For executing the speaking activities, it needs the response from listener or another speaker. To improve the speaking skill there are combinations of activities to promote oral skills in the class room situations, like Group discussion, small speeches, role play and brain storming, etc. It is the task of the teacher to make some arrangements in the class where students like their real time communication. The teachers have to motivate them by providing activities related to daily life and to make all the students participate. By practicing these activities, the speaking skill will improve and they can communicate effectively at any juncture.

\section{To develop speaking skills}

It is essential to understand the paralinguistic features, Verbal practice, explaining objects/situations/people, to participate individual and group activities like debate, group discussion, extempore, role play, public speaking, and Just a Minute (JAM) Sessions.

\section{Reading}

Reading is important to learn new things, new information, and new ways to achieve things. Through reading we can understand the world more and more and to create structured path towards better understanding and better actions to take in the near future. The more we read the more we understand. The reading also increases the understanding of the rules of life. Through better reading skills we can adapt, adopt and accommodate the society in a better way. Thus it is essential for students to have their reading skills well developed. Reading skills can be developed, only if the students can participate in it themselves. Thus the language teachers have to be a facilitator in enhancing the students'classroom activities that concentrates on their reading skill set. It is imperative to enhance the students' skill set to a level that they can,

- Skim the text.

- Read and understand the textual materials.

- Understand the gist of an argument.

- Infer the verbal and related meaning.

- Recognize the harmony, consistency and stress of sentences.

- Identify the topic sentence.

Dauzat defines reading is "a process of involving psychological activity embedded in other communication skills and adapts graphic stimuli (letters) into meaningful thought" [10]. As the process of constructing meaning from texts, It is multifaceted in its process involving word recognition, comprehension, fluency and motivation.

- Word acknowledgement - Identifying the words

- Comprehension-Constructing and understanding the text

- Fluency-Coordinating the words and framing meaning.

To develop word recognition Skills

- The students must familiar with phonemic awareness.

- Should be able to know the braking and manipulation of sounds in words. Eg.feet has three sounds/f/,/e/,and/t/

- Should be able to use and understand some sounds that is a listed code

- S and h to make/sh/sound

- Should be able to recognize the familiarity of letters, words and phrasesto arrive at their comprehensive relationship and function.

- Should be able to analyze and understand words and speaking patterns.

- Should be able to develop the vocabulary skills.

\section{B) To develop comprehension skills}

The students should know the background knowledge about many topics particularly current affairs and the strategies for constructing meaning from the text.

C) To develop fluency skills

In order to enhance the fluency of utilising language one should keep the following as their base.

a. Should have a high level of accuracy in word recognition.

b. Ability in knowing the usage of phrasing and expression helps in improving the fluency in utilising the language.

\section{Writing}

Writing is considered as the most important skill in communication. According to Chakraverty, Writing is defined as "a philosophical activity that needs plenty time to think about the unambiguous topic and to examine and classify the background knowledge" [11]. In the ELT 
Paradigm, teaching writing is called a creative skill because, it depends on the construction of language. Many people have a wrong notion that a good grammatical knowledge is enough for achieving high level of written English competence. On the other hand, writing skill requires not just a good knowledge of the grammatical system but it requires a vast knowledge in verbal and through understanding of the topic given and collection of organizational skills."English writing is difficult for native language students, and it is definitely more challenging for foreign language students" [12].

Rao considers the two aspects that are enhanced by writing. First is for motivating the students' thinking, organizing ideas, and developing their ability to summarize, analyze and criticize. Second it reinforces Students' learning, thinking and reflecting on the English Language. [13]

\section{To develop the Writing skills}

- One should have a sound knowledge in grammar and a wide-ranging verbal knowledge.

- One needs to understand the literal meaning of the words and structural accuracy for effective writing.

- Acquiring wide knowledge in vocabulary, current affairs and organizational skills in addition to that of grammar.

- The supreme level of writing in English can be attained only by toils and turns.

\section{CONCLUSION}

The world moves fast today and engineering functions as its fuel. It is an acknowledged fact that engineering has its hand in every field that enhance and optimize the lives of people. From agriculture to space research engineering marvels has never failed to work its wonder. It is pride brimming moment to realize that India one among the fast growing nations has been producing able engineers in different fields. Indians hands, like engineering has never ceased to mark its signature in the fast growing fields of the world. On consideration to the number of freshers getting placed annually we could only but acknowledge that a lot of Indian potential gets stagnated due to the inability to communicate effectively. Thus it is mandatory for the Indian engineering students to have a good exposure in language in a way that they improve their communication skill set. Concentrating, aiding and enhancing the LSRW from the start besides the curriculum would result in the success of the students as well as the organization. Direct stimulation in LSRW would result in the indirect way of making a graduate to have all the desired qualities that an Industry needs.

\section{REFERENCES}

1. Sharma, A. (1999). Problems and Solutions of Teaching English. New Delhi: Janki Prakashan.

2. Lumsdaine, E., \& Lumsdaine, M. (1995). Creative Problem Solving Potentials. IEEE , 13 (5), 4-9.

3. Narsee, S. (2000). Beyond a Shadow of Doubt: Making a Case for Humanities and Social Sciences in the Engineering Curriculum. Southern African Conference on Engineering Education, (pp. 83-88). Vamderbijl Park, South Africa.

4. Luiz, A., Carlos, A., Jose, A., Costa, C., \& Leopoldo, R. (2004) University-Industry Collaboration as a Strategy for Engineering
Education. International Conference on Engineering Education, (pp. 16-24). Gainesvile, Florida.

5. Tyanjala, P., Soltte, V., Niemen, J., Lonka, K., \& Olkinuora, E. (2006) From University to Working Life: Graduates' Workplace Skills in Practice. In Higher Education and Working Life. Collaborations, Confrontations and Challenges. Amsterdam: Elsvier. [6] Szpytko, J., \& Harrison, D. (1996). Quality Assurance within Engineering Higher Education. EQAS' 96. Oficyna Cracovia, Krakow.

6. Grabowski, L., \& Szpytko, J. (2000). Some Observations on Engineering Education via Industrial Needs. Conference on Engineering Education (pp. 83-88). Krakow: AGH University of Science and Technology.

7. Nur, R., \& Syarifuddin, R. (2018). Designing an Instructional Model of Youtube-Based Materials of Listening Comprehension at Umpar Indonesia. Asian EFL Journal , 20 (7), 94-108.

8. Rahman, S. T., \& Samanhudi, U. (2018). Designing an EFL Speaking Class with a View to Critical Thinking Development. Asian EFL Journal , 20 (11), 127-131.

9. Dauzat. (1981). Reading: The Teacher and The Learner. New York: Wiley.

10. Chakraverty, A., \& Gautam, K. (2000). Dynamics of Writing. Forum 38 (3).

11. Lei, R.-W. (2014). A Case study of Taiwanese college teachers' group exploring narrative pedagogy. Asian ESP Journal (Special Issue), 34-71.

12. Rao, Z. (2007). Training in Brainstorming and developing Writing Skills. ELT Journal , 61 (2).

\section{AUTHORS PROFILE}

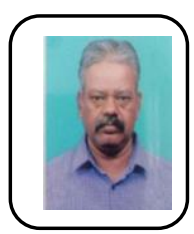

Dr. K. Gurusamy, Associate Professor in the Departmen of English, Kalasalingam Academy of Research and Education ,Krishnankoil, Virudhunagar District,Tamilnadu,India, has completed his graduation, post-graduation and M.Phil. in English Literature from Madurai Kamaraj University, Madurai, India. He was awarded Ph. D. at Kalasalingam Academy of Research and Education, Krishnankoil, India on March 2017, on the topic entitled English Language Teaching with Special reference to Technical communication..He has been teaching English for the Engineering students for more than a couple of decades and also teaching English literature to the UG, PG and research scholars. He has guided more than $10 \mathrm{M}$. Phil. scholars and several M. A. projects. His research area includes English Language Teaching, Indian writing in English, Post Colonialism and Modern Literature. He has published 5 papers in International refereed journals and among them, 2 papers are UGC approved. He has participated in more than 10 conferences and workshops in both National and International levels. He is an authorised trainer for Cambridge ESOL Examinations, and has been training the students for BEC (Business English Certificate) Examinations for more than a decade. He is an authorised Speaking Examiner for BEC Speaking Examinations from 2018 onwards. He is a life member of ISTE.

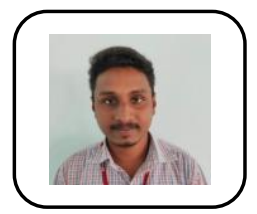

Mr.A.Gokula Hari, Research scholar in the Department of English, Kalasalingam Academy of Research and Education ,Krishnankoil, Virudhunagar District,Tamilnadu,India, has completed his graduation and post-graduation in English Literature from Madurai Kamaraj University, Madurai, India. He was awarded M.Phil, at Kalasalingam Academy of Research and Education, Krishnankoil, India on March 2019,on the topic entitled Salman Rushdie's Shame. His research area includes Indian writing in English, Post Colonialism, Post Modernism and Modern Literature. He has published 2 papers in International refereed journals and both are approved by the UGC . He has participated in conferences and workshops in both National and International levels. 